\title{
Surgical and Dysmorphological Aspects of Abdominal Wall Defects
}

\author{
Ágnes Harmath, Júlia Hajdú, Erik Hauzman, Barbara Pete, Zoltán Papp
}

First Department of Obstetrics and Gynecology, Semmelweis University Faculty of Medicine, Budapest, Hungary

Correspondence: Ágnes Harmath, First Department of Obstetrics and Gynecology, Semmelweis University Faculty of Medicine, H-1088 Budapest, Baross str. 27, H-1442 Budapest, PO Box 104, Budapest, Hungary, Phone/Fax: (36-1)266-0507 e-mail: harmath.agnes@noi1.sote.hu

\section{ABSTRACT}

Keywords: Abdominal wall defects, gastroschisis, omphalocele, bladder exstrophy, cloacal exstrophy, complex anomalies associated with abdominal wall defects.

\section{INTRODUCTION}

Fetal abdominal wall defects have an incidence of 17 to 22 per 100,000 live births. ${ }^{1,2}$ The most frequent forms are gastroschisis and exomphalos, but this group also includes body stalk anomaly, cloacal and bladder exstrophy, and pentalogy of Cantrell. ${ }^{3}$ Although investigators have attempted to find common embryologic etiology to these various defects, the anatomy, the incidence, the associated malformations, and chromosomal abnormalities strongly suggest that despite their similar appearances these are essentially different entities. ${ }^{4}$ Some of them may also be associated with chromosomal and other malformations. Prenatal diagnosis is made using ultrasound imaging. The prenatal detection rate of anterior abdominal wall defects is reported to be as high as 86 to $90 \%{ }^{5}$ Ventral wall defects may result in elevation of maternal serum alpha fetoprotein (AFP) levels; ultrasonographic examination is an important part of the evaluation of pregnancies with elevated AFP.

Prenatal diagnosis provides the opportunity for the parents to discuss the problem not only with the obstetrician, but the pediatric surgeons and neonatologists as well. The diagnosis of a surgically correctable anomaly is extremely stressful and creates a sense of insecurity. The long-term outcome of infants with isolated abdominal wall defects is good. ${ }^{3,6,7}$ Despite this fact, Austrian investigators have reported that $40 \%$ of parents with a child with gastroschisis decided against having another child. $^{8}$

\section{GASTROSCHISIS}

The term, derived from Greek, means "belly cleft". It was first reported by Bernstein in $1940 .^{9}$
An increase in the incidence of gastroschisis has been noted worldwide. Currently, the reported incidence ranges from one in 10,000 to 15,000 live births. ${ }^{10-13}$ Much of the increase was detected earlier, in the 1970's and 1980's, but similar trends exist for more recent years. ${ }^{14}$ Suita et al studied the incidence of the malformation in Japan between 1975 and 1997. They found a more than threefold increase ( 0.131 to 0.467 per 10,000 births). ${ }^{15}$ Rankin et al in a retrospective study of the Northern congenital abnormality survey data reported an almost fourfold increase in incidence from 1986 to $1996 .{ }^{2}$ In a recent study, an increase in the incidence of gastroschisis over the past ten years was noted though this increase did not reach statistical significance. ${ }^{11}$

Risk factors for gastroschisis include young maternal age at delivery, low socioeconomic status, smoking, maternal malnutrition, low body mass index, use of aspirin and recreational drugs, radiation damage at the preimplantation stage, bronchodilator use during pregnancy, prior history of gynecological infection/disease, and paternal age. ${ }^{11-13,16,17}$

The exact etiology is largely unknown. Most cases are sporadic. Familial occurrence, in some cases autosomal dominant inheritance with variable expressivity, or autosomal-recessive inheritance has been documented in the epidemiology of gastroschisis. $^{9,18}$

The exact point during the embryonic period when this defect develops is uncertain. Many embryologists suggest it occurs between the 5th and 10th week of gestation. Several pathogenic theories have been put forward and recently reviewed. Shaw in 1975 hypothesized that the abdominal wall cleft results from the rupture of the amniotic membrane at the umbilical cord base during the extra-abdominal phase of small intestinal development. ${ }^{19}$ Five years later deVries et al that proposed that the premature atrophy of the right umbilical vein, which normally involutes between the 28th and the 32nd day after conception, causes localized mesenchymal damage to the abdominal wall, with the failure of epidermal repopulation leading to gastroschisis. ${ }^{20}$ Hoyme et al proposed that the disruption of 
the right umbilical artery underlies most gastroschisis cases. This idea is supported by the high association risk of other specific anomalies that are thought to result from intrauterine vascular disruption (e.g. small intestinal stenosis or atresia). ${ }^{21,22}$ The other commonly proposed etiology is the disruption of the omphalomesenteric artery. Feldkamp et al recently suggested another hypothesis, according to which gastroschisis is the consequence of failure of one or more folds responsible for abdominal wall closure. This failure "impedes the merging of the yolk sac with the connecting stalk. Then, as gut development continues, part of the primary intestinal loop attached to the vitelline duct herniates into the amniotic cavity instead of the umbilical cord". ${ }^{23}$ Recently, Lammer et al presented the endothelial nitric oxide synthase pathway and its relationship to vasculogenesis, suggesting that disruption of this pathway by any environmental or genetic exposure may present a pathogenetic model for gastroschisis. They found four genes that showed association with gastroschisis: nitric oxide synthase 3 (NOS3), intercellular adhesion molecule 1 (ICAM1), atrial nitric oxide peptide (NPPA), and alpha adducin-1 (ADD1). Among them, NOS3, which is the endothelial isoform of nitric oxide synthase, seems to be an especially good candidate gene. $^{24}$

Gastroschisis can be seen on prenatal ultrasound and diagnoses as early as 11 weeks of gestation have been reported. ${ }^{1,6,7,25}$ The diagnosis relies on the demonstration of herniated visceral organs adjacent to the anterior abdominal wall and the dilatation of the intra-abdominal proximal bowels. The location of the defect in gastroschisis is usually on the right but left-sided defects have been reported. The size of the defect is generally 3 to $5 \mathrm{~cm}$. Hepatic herniation is rare. The herniated organs are not covered by a membrane, they float freely in the amniotic cavity (Figs 1 and 2). The umbilical cord is normally connected to the abdominal wall. Polyhydramnios, probably because of the impaired gastrointestinal transit, can be detected, ${ }^{18}$ but oligohydramnios occurs in $30-40 \%$ of cases. Meconium is frequently found in the amniotic fluid.

If the diagnosis is established prenatally, it is advisable to deliver in a center which has close connection to a pediatric surgery department. There is controversy on the preferred mode of delivery. In the international literature, the rate of cesarean section in prenatally diagnosed gastroschisis cases varies between 28.0 and $96.6 \%$. There is no evidence of any advantage of elective cesarean section over vaginal delivery with regard to neonatal outcome. Cesarean section should be reserved for obstetric indications and acute fetal complications only. The usual recommendation for timing of delivery is related to gestational age when lungs are mature, but long prolongation

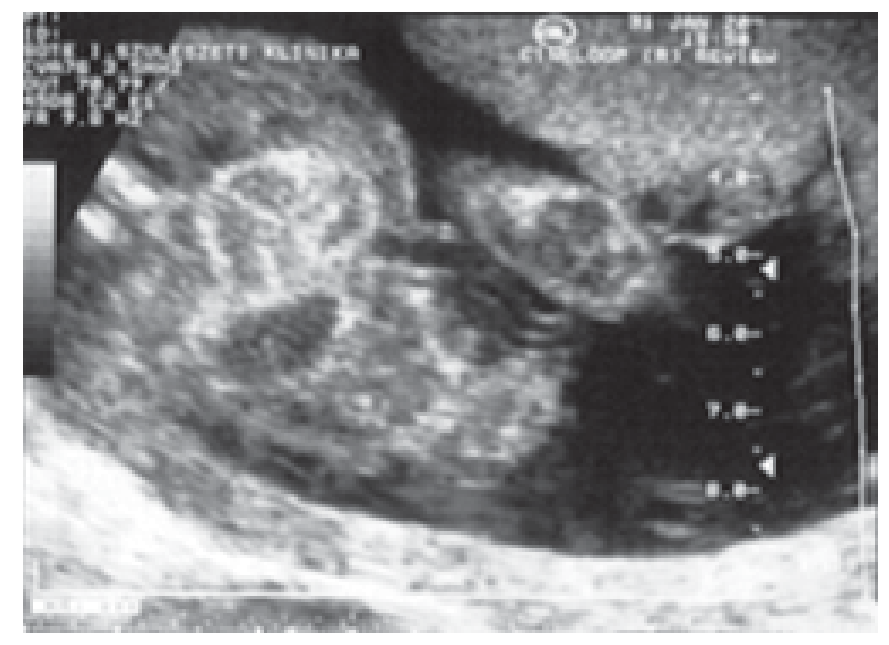

Fig. 1: Fetal gastroschisis-freely floating bowel loops in the amniotic cavity

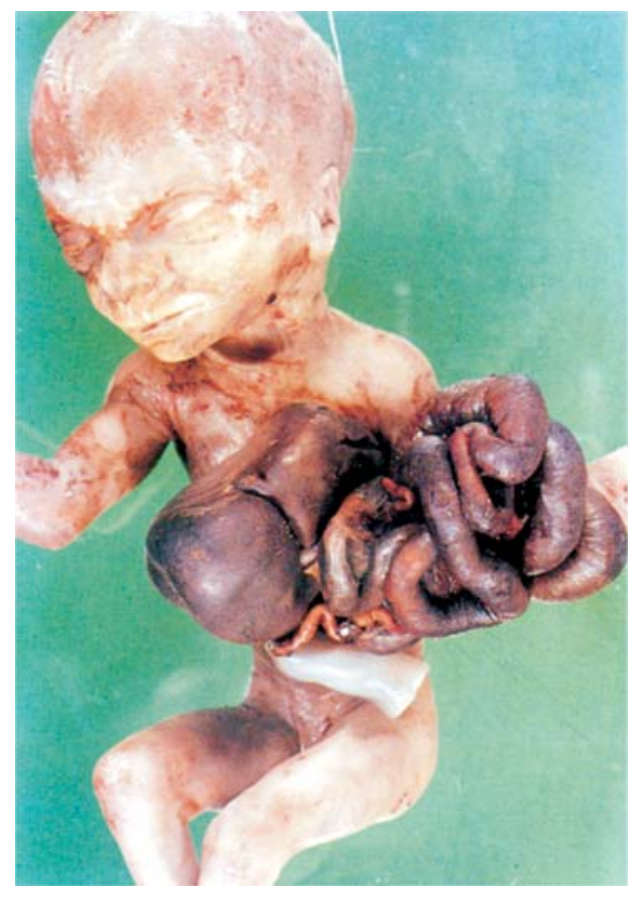

Fig. 2: Severe gastroschisis: the herniated organs are not covered with by membrane. The umbilical cord is not involved

of intrauterine life may increase of gastrointestinal morbidity. 4,6,7,26-29

The herniated bowel loops are coated by an inflammatory fibrotic peel. This results in thickening of the bowel wall, matting of the intestines, decreases bowel motility, and may cause luminal obstruction. Intestinal damage is independent from the size of the defect. Histology shows no venous stasis, ischemic lesion or any difference in the degree of the bowel wall edema. 
The damage is caused by other intra-amniotic factors such as meconium, amniotic fluid $\mathrm{pH}$, and amniotic fluid $\beta$-endorphine. Mahieu-Caputo et al observed that the amniotic fluid $\beta$ endorphine level correlates with the severity of the deformity. It is hypothesized that this fetal hormonal response could result from stress or pain caused by bowel damage. ${ }^{6,30}$ At birth, probably because of chronic intestinal inflammation, infants have low serum albumin and total protein levels.

Postnatal evaluation classifies gastroschisis into 2-groups, which include simple and complex cases, respectively. One third of the cases are complex with associated bowel pathology such as malrotation, volvulus, infarction atresia, perforation or stenosis. ${ }^{6}$ Borgstein in 2001 described gastroschisis minor as a small abdominal wall defect to the right of the umbilical cord insertion with only a small omental protrusion. ${ }^{31}$ There is another rare form, the so-called “closed gastroschisis”. In these cases there is significant closure of the abdominal wall defect around the prolapsed bowels. This abdominal ring closure can cause a number of midgut abnormalities (vanishing midgut, small right-sided mummified midgut or simple luminal occlusion without any vascular impairment). ${ }^{6}$

After birth, the abdominal wall defect should be surgically addressed as soon as possible. Gastroschisis closure is dependent on the amount of visceroabdominal disproportion and the intra-abdominal pressure. Primary closure is preferred; it can be achieved in about 60 to $70 \%$ of cases. ${ }^{7}$ Increased abdominal pressure (higher than $20 \mathrm{~cm} \mathrm{H}_{2} \mathrm{O}$ ) requires other techniques such as using artificial patch, mobilized lateral skin flaps or staged silo closure. ${ }^{4,6,26}$ The neonatal management is directed towards limiting the fluid and protein loss and preventing hypothermia. Gastrointestinal decompression, intravenous albumin and fluid infusion, broad spectrum antibiotics, and correction of metabolic acidosis are recommended.

The survival rate is reported between 85 and 95\%. With current neonatal intensive care, parenteral nutrition, and pediatric surgery techniques, there has been a decrease in mortality rates, ranging from 2.4 to $5.3 \%$ in the past decade. ${ }^{7,11,26,29,32}$

Nowadays the cosmetic appearance is also important. Patel described a technique of closure which allows for almost scarless appearance of the abdominal wall and preservation of a midline umbilicus. ${ }^{33}$

Traditionally, gastroschisis is considered a malformation that is generally not associated with an increased risk of chromosomal abnormalities or extragastrointestinal malformations. However, some studies contradict this assertion. Associated malformation rates of 5.3 and $20.8 \%$ were reported by Rankin et al and the EUROCAT studies respectively. The associated anomalies may involve other organ systems, such as the genital, urinary, cardiac, respiratory, and central nervous system; the most common forms are hydronephrosis, arthrogryposis, hypoplastic gallbladder, Meckel diverticulum, and intrauterine growth retardation. ${ }^{1,2,6,26,34,35}$ An international study on the basis of case-by-case information from 24 birth defect registries of countries located in Australia, China, North, Central and South America, and Europe, found that $14 \%$ of cases were nonisolated, $2 \%$ were associated with recognizable syndromes and $12 \%$ were multiple congenital anomalies. The multiple anomalies showed essentially two patterns, which were named pattern A and pattern B; those with similar characteristics with limb-body wall complex (pattern A) and those with the OEIS (omphalocele, exstrophy, imperforate anus, and spinal defect) complex (pattern B). The groups are characterized by gastroschisis plus two or more of the following malformations: in case of pattern A, anencephaly/encephalocele, limb reduction defects, hydrocephaly, cleft lip +/- palate, while in cases of pattern B, spina bifida, ambiguous genitalia, anorectal atresia, and kidney agenesis can occur. The rate of arthrogryposis proved to be $0.5 \%$, which can support the notion that the pathogenesis of these two defects may be related to vascular compromise. ${ }^{36}$ Intrauterine growth retardation by prenatal ultrasound may be overestimated because of smaller abdominal circumference measurements. Intestinal atresia or other bowel problems may be present in as many as 10 to $25 \%$ of patients. ${ }^{4,6}$ Japaraj et al found that polyhydramnios was associated in a significantly higher rate with severe bowel complications such as atresia, perforation, and necrotic segment in the neonatal period. ${ }^{37}$ Some children, approximately $10 \%$ of cases, have significant morbidity from prolonged gastrointestinal dysfunction. $^{10}$

Long-term studies suggest that physical and intellectual development is usually unimpaired. ${ }^{7}$ Adhesions within the peritoneal cavity leave the infants at risk of adhesive smallbowel obstruction even into adult life. Gastroesophageal reflux disease has been documented as a cause of long-term gastrointestinal problems. ${ }^{12}$

\section{OMPHALOCELE}

Omphalocele is also known as exomphalos. It is one of the most common anterior abdominal wall defects. The overall incidence is approximately 1 in 300 to 10,000 births if the numbers of live births and stillbirths are combined. The incidence is 20 times greater in stillborn than in live-born infants. $6,18,38,39$

Nonsyndromatic cases are sporadic with the recurrence risk of less than 1\%. Familial occurrence with X-linked, autosomal dominant or recessive pattern of inheritance has been reported. 
The incidence of omphalocele has been found to vary among geographic location, urban versus rural setting, and ethnic groups. ${ }^{4,6,18,40}$ Risk factors include both higher ( $>35$ years) and younger ( $<25$ years) maternal age, use of assisted reproduction technology, maternal febrile illness, and inadequate periconceptional vitamin (folic acid) intake., ${ }^{6,38,41,42}$ There are no known teratogens associated with omphalocele although it has been suggested that misoprostol, and valproic acid exposure are possible teratogens..$^{39,40}$

The prenatal detection rate is generally given between $75 \%$ and $90 \% .^{5,7,40}$

Physiologic herniation is observed between the 8th and the end of 11th week. It is round or oval, small, and homogeneous. Omphalocele can be suspected in this age of gestation if the herniated sac is bigger than $7 \mathrm{~mm}$. Early diagnosis can be made through either vaginal or abdominal ultrasound from the end of first trimester. The abdominal contents are enclosed, located at the base of umbilical cord, and the liver is often included. Color Doppler examination can help locate the exact site of the malformation. Basically the herniated organs are gut loops, and 2D is superior to 3D ultrasound for the detection of the content (Figs 3 to 5). It may be accompanied by polyhydramnios (30\%). Ascites is a frequent accompanying finding. ${ }^{40,43}$ The high number of accompanying congenital heart malformations and the frequent occurrence of abnormal direction of cardiac axis necessitates detailed fetal echocardiography. ${ }^{44,45}$ Volumetric calculation of the lung volume and the exteriorized abdominal contents can be useful in planning delivery, neonatal and pediatric surgery management. ${ }^{38}$

The optimal mode of delivery is controversial. An elective cesarean section avoids the compromise of intestinal blood supply at birth, avoids exposure to the vaginal flora, and allows

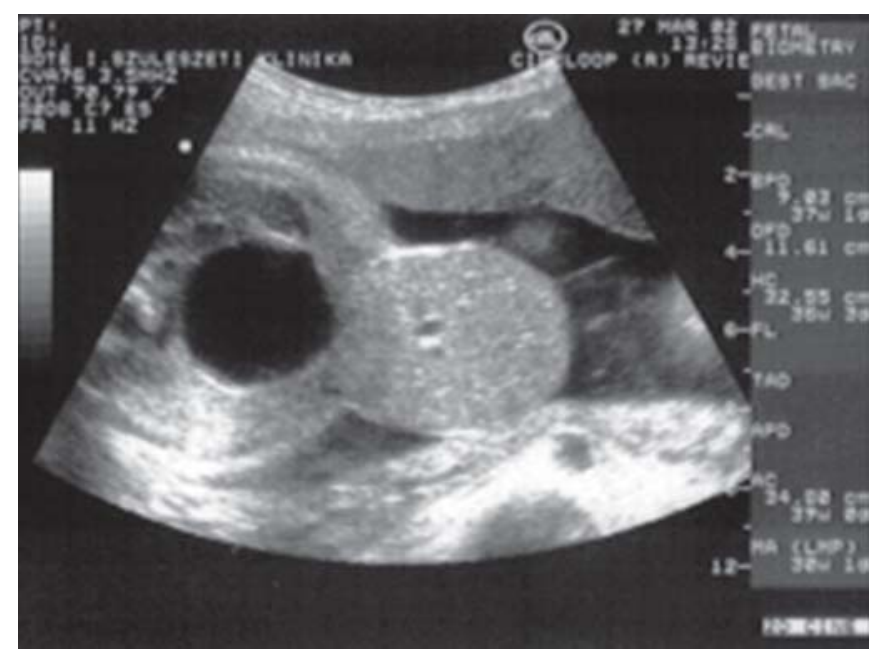

Fig. 3: Fetal large omphalocele with liver in it (2D)

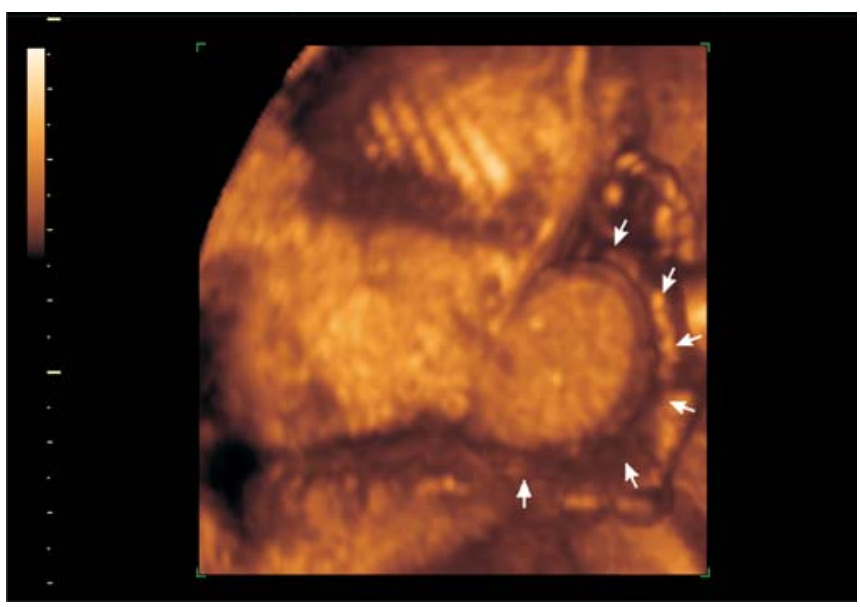

Fig. 4: Fetal large omphalocele with liver in it (3D)

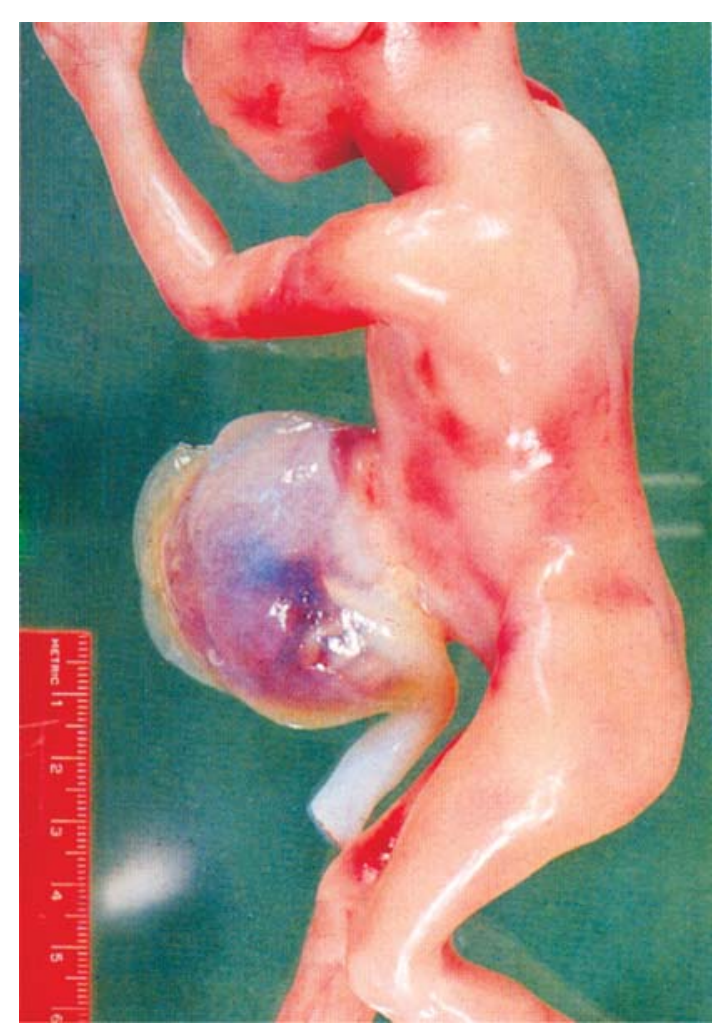

Fig. 5: Large omphalocele in a 17-week-old fetus

planned delivery. Although prospective randomized studies demonstrated no evidence of any improvement in outcome with cesarean section, a statistically significant increase can be observed in cesarean section rate. Cesarean section is recommended in cases when the liver is herniated because of the risk of injury to the liver that can cause lethal hemorrhage and to avoid dystocia., ${ }^{4,29,38}$ In cases where only bowels are herniated, vaginal delivery can be attempted. ${ }^{4,5,7,29,38,40}$ 
The size of an omphalocele can vary widely (Fig. 6). Herniated abdominal structures include some bowel loops, but can also involve liver and biliary structures. The defect is identified as a "giant omphalocele" when the liver and biliary structures are part of omphalocele. The extruded abdominal contents are covered by a two-layer membrane, onto which the umbilical cord inserts. The sac should be kept moist by wrapping it in sterile cloth soaked in warmed normal saline until surgical covering or complete repair. Prompt decompression of the stomach is necessary, followed by intermittent gastric suction. ${ }^{4,6,18,39}$ Primary repair and direct closure is the treatment of choice. If the ventilation pressure during surgery exceeds 20 $\mathrm{mm} \mathrm{Hg}$, there are signs of kidney failure or lividity of the lower limbs can be observed, artificial material should be used primarily. Alternatively, the silo technique or the novel suspension technique can be employed. 6,7,46

Omphalocele can be associated with other malformations in up to $74 \%$ of cases, most commonly (in up to $50 \%$ of fetuses) cardiac defects that include muscular ventricular septal defect, atrial septal defect or aortic coarctation. ${ }^{35,41,44,47}$ Gastrointestinal anomalies occur in $40 \%$ of cases. Musculoskeletal, genitourinary, and central nervous system anomalies are commonly associated too. ${ }^{6,35}$ In 2001, a search of the London

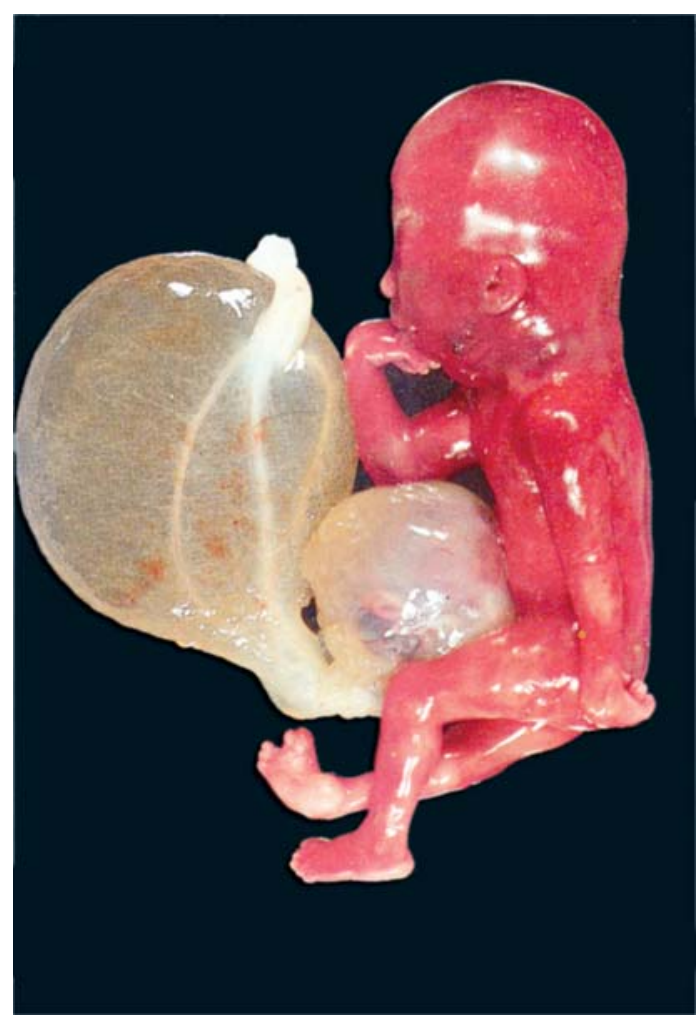

Fig. 6: Omphalocele and an enormous cystic abnormality of the umbilical cord
Dysmorphology Database by Winter and Baraitser resulted in 64 syndromes in which omphalocele occurs. ${ }^{48}$ For example, an omphalocele can be part of Beckwith-Wiedemann syndrome, pentalogy of Cantrell, and the OEIS complex. Depending on the gestational age chromosomal defects are seen in approximately 15 to 40 percent of omphaloceles. The most common type of aneuploidy is trisomy 18 and 13 followed by triploidy and Turner syndrome. Aneuploidy is more often found in smaller omphalocele cases. ${ }^{38,48,49,50}$ It is suggested that there is a correlation between the defect size and the associated malformations. Omphaloceles that contain the liver are more often accompanied with cardiac, renal, and limb anomalies. In contrast, smaller omphaloceles, containing only intestines, coexist with gastrointestinal and central nervous system malformations. ${ }^{38}$

The outcome of the patients largely depends on the severity of associated anomalies. The termination rate is generally given between 30 and 70\%. ${ }^{5,35,38,41,47}$ The mortality rate is reported to be $61 \%$ for cases with associated anomalies, and only 15.5 to $20 \%$ without. ${ }^{6,7,29}$ In the absence of significant additional anomalies, the hospital stay is generally shorter; the rate of complications-hypomotility, cholestatic liver-is lower than in patients with gastroschisis. ${ }^{4}$

\section{BLADDER EXSTROPHY}

Bladder exstrophy, also known as exstrophy-epispadiasis complex, is a rare and severe anomaly. Its frequency is $1 / 25.000$ $1 / 50.000$ births, with a 2-3:1 male to female ratio. ${ }^{18,40,43,51}$

It is the failure to develop a cloacal membrane and failure of the midline fusion of myotomes during the second and third month of gestation. The cloaca, which is the proximal end of the allantois, is divided by the urorectal septum into the urogenital sinus and the anorectal canal. The anterior cloaca-the urogenital sinus - narrows and elongates to form the bladder and urethra. The cloacal membrane forms the caudal ventral wall. As the cloacal membrane regresses, two mesodermal ridges (urorectal septum) migrate to the midline. If the cloacal membrane does not retract normally, the mesodermal ridges fuse inferiorly, and the cloacal membrane remains the ventral wall of the bladder until the 9th week of gestation when it regresses and the posterior wall of the bladder is exposed. At the end, the ventral abdominal wall and anterior bladder wall are absent. In addition, the pubic bones are separated; there is an epispadiasis in boys or cleft clitoris and separated labia in girls. ${ }^{52,53}$

The size of the averted bladder is quite variable, ranging from a small portion of the trigone to complete protrusion of the posterior wall of the bladder. Clinically, the minor form of this abnormality takes the form of epispadiasis. ${ }^{18,40,52}$ 
Most cases of bladder exstrophy are sporadic. There are no known teratogens associated with this condition. The inheritance is multifactorial. The risk of an affected parent having an affected child is about 1 to 70 live births. It is 500 times greater than the risk of the general population. The calculated recurrence risk is $1 \% .{ }^{18,52,54}$ Associated anomalies, such as unilateral renal agenesis or horseshoe kidney, are rare. ${ }^{18,52}$

The prenatal diagnosis of bladder exstrophy is difficult. It should be suspected any time a bladder cannot be visualized in a fetus with a normal amount of amniotic fluid and kidney. The fetal bladder can be identified as early as 11 to 12 weeks of gestation. The persistent absence of the bladder should be considered as abnormal from the 15th week. The exstrophy itself may not be easily visualized. On sagittal view, a small mass, representing the extrusion of the posterior bladder wall, may be identified. The mass does not contain cystic areas. Separation of pubic rami may be reflected by abnormal widening of the iliac crest. The umbilical cord insertion is generally in a lower position. In male fetuses, the external genitalia may be in a more cephalad location than usual. The umbilical arteries are situated alongside the bulging mass. ${ }^{55} 3 \mathrm{D}$ ultrasound did not improve significantly the prenatal detection rate of genitourinary anomalies, but it is useful in assessing the volume of the urinary bladder. ${ }^{18,52,54-56}$

In cases diagnosed prenatally, delivery is recommended in specialized centers where immediate reconstruction of the exstrophy can occur. Due to the rarity of this condition, the surgical repair should be performed only in very experienced centers. ${ }^{57}$ After birth, the bladder mucosa is very friable and easily denuded, so it is important to keep it under wet and sterile conditions immediately after delivery. Postnatal treatment focuses on the reconstruction of the bladder, abdominal wall, and genitalia. The classical surgical procedure is "staged reconstruction", in which the initial step was the closure of the bladder plate and posterior urethra, with the subsequent step being the repair of epispadiasis, and the final step being reconstruction of the bladder neck. However, a complete primary repair of bladder exstrophy is now available. This procedure involves the closure of the bladder plate and the abdominal wall combined with epispadiasis repair. In some cases, urethral reimplantation is also performed. Borer et al reported that complete repair is the treatment of choice, which includes approximation of the pubis too. ${ }^{58}$ If primary repair is undertaken within the first 72 hours of life and if the diastasis is less than $4 \mathrm{~cm}$, the pelvic ring can be easily formed under anesthesia and the osteotomy can be avoided..$^{59,60}$

Specialized postoperative intensive care unit and specialized nursing care are required. Patients should be kept pain-free, long crying spells and abdominal distension should be avoided so that sutures do not cut through the infantile soft tissue, thus decreasing the risk of complications.

Bladder stones develop secondary to recurrent urinary tract infections, urinary stasis, and bladder augmentation in 24 to $72 \%$ of patients. Bladder dehiscence is a relatively rare complication. Pyelonephritis, upper tract function scarring, and hydronephrosis can occur mainly in patients with ureterosigmoidostomy. After complete primary repair, the rate of urethrocutaneous or vesicocutaneous fistulas is about $10 \%$ and resultant hypospadiasis is about 40 to $45 \%$. In one third of adult patients, epididymitis presents as a late complication. Neuropathies, pressure ulcerations, skin infections, joint pain, nonunion or leg length inequality arising from osteotomy and traction devices can arise. ${ }^{60,61}$

Bladder neck reconstruction is performed at the ages of 4 to 5 years when an appropriate capacity had been gained. ${ }^{57}$ Urinary incontinence rates after repair of bladder exstrophy vary between 12 and $83 \%$. The type of operation, the need of concomitant augmentation and the length of follow-up are highly variable. ${ }^{60}$

Follow-up data for the complete primary repair are not as readily available as those for staged patients. Borer et al found that $63 \%$ of patients 4 years old or older will likely need bladder neck reconstruction, while Hammouda and Kobt reported a continence rate of $73 \%{ }^{58,61}$

The overall prognosis is good. ${ }^{52}$ Patients grow into adulthood and have an acceptable social adjustment. ${ }^{18}$ There appears to be an increased risk of malignancy, especially in patients who have had urine diverted into the fecal stream. In one report, the risk of neoplasia in patients born with bladder exstrophy is $17.5 \%$ and has a 65 times higher rate of malignancyrelated mortality than in members of the normal population. ${ }^{60}$

\section{CLOACAL EXSTROPHY}

The cloacal exstrophy is a complex and severe anomaly, in which both the urinary, genital, and intestinal systems are involved as a consequence of the maldevelopment of the urorectal septum. It occurs when the cloacal membrane regresses before the urogenital septum develops. Both the bladder and bowel become exposed. The defect is complex, including two hemibladders separated by bowel mucosa, each with its own ureteral orifice. The symphysis is widened and the external genitalia are separated. . $^{18,40,52}$

The incidence is $1 / 200,000$ to $1 / 400,000$ live births, without sex preponderance. The incidence is significantly higher in monozygotic twins. Because of the severity of this condition, survivors do not have preserved reproductive function. Genetic inheritance is possible but unknown, therefore this abnormality 
is considered sporadic. There are no known teratogens associated with this condition. The most common associated malformations are neural tube defects, malformations of the genitourinary and renal system, and omphalocele. . $^{18,40,43,62}$

Prenatal diagnosis of this condition may be difficult. The normally appearing bladder is absent, but examination of the umbilical arteries with color Doppler can help locate its position. An intra-abdominal cystic mass is usually visualized in the sagittal plane. Urinary ascites or hydronephrosis can be seen. In female fetuses, fetal ascites occurs at an early stage due to the escape of urine through the fallopian tubes into the abdominal cavity. Later, occlusion of the tubes occurs and the cystic pelvic mass compresses the ureters. The amniotic fluid may be increased, reduced or normal. A specific but, because of intermittent herniation of the intestinal loops, inconsistent sign is the elephant trunk-like image. It is a wavy cord-like segment of small intestine protruding from the ventral wall defect, resembling the trunk of an elephant. ${ }^{40,52,62}$

In case of early diagnosis, couples generally request termination of pregnancy. In milder forms of this anomaly, surgical correction may be attempted after delivery, by closing the bladder and establishing a colostomy. Later, extensive surgeries are required. ${ }^{40}$ The survival rate is generally reported between 50 and $90 \%{ }^{18,52}$

\section{COMPLEX ANOMALIES ASSOCIATED WITH ABDOMINAL WALL DEFECTS}

The three complex anomalies with abdominal wall defects (body stalk anomaly, pentalogy of Cantrell, OEIS complex) are addressed below in the chronologic order of appearance during embryologic development. Because of the challenging and difficult prenatal diagnosis of these complex anomalies, all types of imaging techniques, including 2D and 3D ultrasound as well as fetal magnetic resonance can be deployed to provide data for correct identification. In case of early diagnosis, extensive counseling, with the participation of obstetricians, pediatric surgeons and neonatologists, must be provided to parents in an attempt to give them the entire spectrum of possibilities, survival rates, and outcomes, including the quality of life.

\section{BODY STALK ANOMALY}

It is also known as limb-body wall complex, congenital absence of umbilical cord syndrome, short umbilical cord syndrome or cyllosmas. ${ }^{40}$ It is a lethal anomaly with different pathogenic theories including the maldevelopment during embryonic folding, early amnion rupture or vascular rupture..$^{40,63,64}$

This abnormality is sporadic and rare. Its incidence is 1 in 14,000 to 42,000 pregnancies. ${ }^{40,43,63,64}$ During the first trimester ultrasound screening (at 10 to 14 weeks of gestation), the incidence proved to be higher with 1 in 7,500 fetuses. ${ }^{63,64}$ The discrepancy can be explained by the high incidence of miscarriage of affected fetuses.

Ultrasound examination may reveal short or absent umbilical cord or evisceration of the abdominal cavity (most often left lateral thoracoabdominoschisis). Associated anomalies include limb abnormalities (partial or complete absence), caudal regression, kyphoscoliosis, midfacial clefts, and neural tube cranial defects, such as exencephaly and encephalocele (Fig. 7). Generally one umbilical artery is missing. The fetus is attached to the placenta and uterine wall. Oligohydramnios can occur. Thickened nuchal translucency is observed during early pregnancy. In such cases, fetal karyotyping is recommended, but in general the karyotype is normal. ${ }^{18,40,63,64}$

These features can be detected by the end of the first trimester, which is important in patient management, since the body stalk anomaly is incompatible with life. In some cases, twin pregnancies have been reported, with positive neonatal outcome of the unaffected infant. ${ }^{63,64}$

\section{PENTALOGY OF CANTRELL}

It was first described as a specific combination of midline supraumbilical abdominal wall defect, defect of the lower sternum,

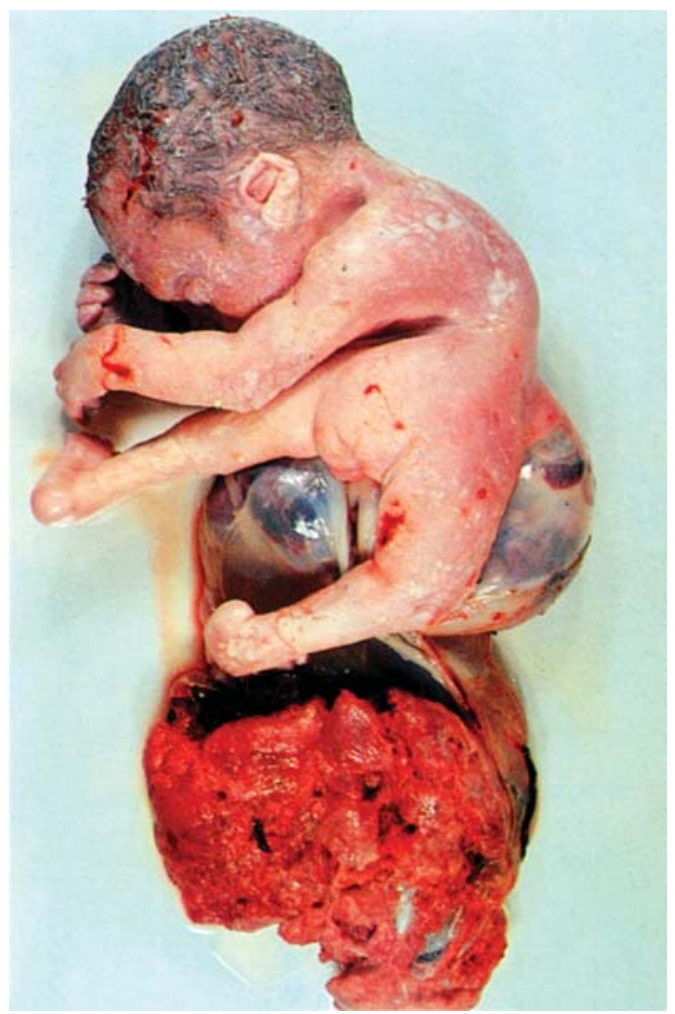

Fig. 7: Limb-body wall complex 
defect of the diaphragmatic pericardium, defect of the anterior diaphragm, and congenital cardiac anomalies by Cantrell in 1958. ${ }^{65}$ It is also known as Cantrell-Haller-Ravitch syndrome. ${ }^{40}$

The precise etiology remains unknown. One hypothesis is that it results from a developmental failure of a segment of the lateral mesoderm at around 14 to 18 days of embryonic life, with subsequent failure in the development of the transverse septum of the diaphragm and the failure in the ventromedial migration of the paired mesodermal folds of the upper abdomen. ${ }^{65,66}$ Expression of the full pentalogy is rare; the estimated prevalence varies from 1/65,000 to 1/200,000 births, affecting male and female fetuses at a ratio of 2:1. Affected females usually present more severe symptoms. ${ }^{43,66-68}$ The risk of recurrence is extremely small. There are no known teratogens associated with this condition. Association with aneuploidy, especially with trisomy 18 , has been described so prenatal chromosomal analysis is highly recommended. ${ }^{40,68,69}$ The thoracoabdominal syndrome including the pentalogy of Cantrell is suggested to be an Xlinked dominant disorder, with mapped Xq24-q27 gene. ${ }^{68}$

Prenatal diagnosis is possible by ultrasound as early as in the 10th and 11th week of gestation but the variable degree of severity of associated anomalies makes it challenging. Suspicion may be raised during the first-trimester scan with the diagnosis of supraumbilical abdominal wall closure defect. Demonstration of ectopia cordis is critical for the diagnosis. Attention must be paid to demonstrate deficiencies in the sternum, diaphragm, and pericardium. Transient pericardial and pleural effusions, nuchal translucency thickening and cystic hygroma have also been reported. 3D ultrasound imaging during the second and third trimesters provides more precise anatomical information for the assessment of the volume and the content of omphalocele and allows a clear assessment of the relationship between the fetus and placenta. ${ }^{40,66,68-70}$ Cantrell pentalogy is frequently accompanied by oligohydramnios. ${ }^{43}$ The characteristic thoracic defect with ectopia cordis and the absence of spinal defects should aid its differentiation from the OEIS complex. ${ }^{48}$

There is controversy in the literature regarding the prognosis. The survival rate, particularly in cases with ectopia cordis, is generally reported quite low. The prognosis depends on the various types of cardiac malformations (ventricular septal defects, Fallot tetralogy, left ventricular diverticulum, hypoplastic left heart syndrome), which are constant features of the pentalogy of Cantrell. ${ }^{40,43,66,70}$ Zidere et al reported on three surviving patients (aged 2, 5, and 8 years) in 2008. In all cases, the heart was initially thought to be ectopic but was noted to be inside the body wall on subsequent scans at 20 and 26 weeks of gestation. ${ }^{70}$

\section{OEIS COMPLEX}

The combination of omphalocele, exstrophy, imperforate anus and spinal defect was first described in 1978 by Carey et al. ${ }^{62}$ It arises from a single localized defect in the early development of the mesoderm that will later play a role in the development of the infraumbilical mesenchyme, cloacal septum and caudal vertebrae. ${ }^{67}$ The "E" may either stand for bladder or cloacal exstrophy. Martinez-Frias et al consider them as part of a "continuum" representing different levels of severity within the same spectrum. ${ }^{49}$ In 2006, Vasudevan et al presented two cases that supported this theory. ${ }^{48}$

Prenatal ultrasound diagnosis is possible, but is a challenging task. The main sonographic findings are exstrophy of the cloaca, large midline infraumbilical ventral wall defect, lumbosacral meningomyelocele and a failure to visualize the urinary bladder. There are secondary findings such as narrow thorax, kyphoscoliotic spine, genitourinary anomalies, clubfeet or single umbilical artery. ${ }^{48}$

It is reported to be a rare anomaly, affecting 1 in 200,000 to 400,000 pregnancies. The real incidence is unknown since many cases are incorrectly diagnosed prenatally; the pregnancies are terminated or end with fetal demise without fetopathology. The etiology is unclear. Usually, this anomaly has sporadic occurrence. It has been reported in siblings, in association with the deletion of 3q12.2-q13.2, in vitro fertilization and in diazepam exposure. These findings suggest etiological heterogenicity with a role for genetic and environmental factors. ${ }^{48,67,71-74}$

In the past, this condition was considered to be almost always lethal. In the absence of other severe malformations, modern surgical and intensive care treatment allows for favorable postnatal survival rates. However, this abnormality is associated with considerable morbidity (life-long colostomy or ileostomy, recurrent urinary infections, severe abnormalities of reproductive organs, paralysis or defects of lower extremities) and psychosocial consequences. ${ }^{74}$

\section{REFERENCES}

1. Calzolari E, Bianchi F, Dol H, Milan M. Omphalocele and gastroschisis in Europe: A survey of 3 million births 1980-1990. Am J Med Genet 1995;58:187-94.

2. Rankin J, Dillon E, Wright C. Congenital abdominal wall defects in the north of England 1986-1996: Occurrence and outcome. Prenat Diagn 1999;19: 662-68. 
3. Arnaoutoglou C, Pasqiuni L, Abel R, Kumar S. Outcome of antenatally diagnosed fetal anterior abdominal wall defects from a single tertiary centre. Fetal Diagn Ther 2008;24:416-19.

4. Weber TR, Au-Fliegner M, Downard CD, Fishman SJ. Abdominal wall defects. Curr Opin Pediatr 2002;14: 491-97.

5. Murphy FL, Mazlan TA, Tarheen F, Corbally MT, Puri P. Gastroschisis and exomphalos in Ireland 1998-2004. Does antenatal diagnosis impact on outcome? Pediatr Surg Int 2007;23: 1059-63.

6. Wilson RD, Johnson MP. Congenital abdominal wall defects: An update. Fetal Diagn Ther 2004;19:385-98.

7. Henrich K, Huemmer HP, Reingruber B, Weber PG. Gastroschisis and omphalocele: Treatments and long-term outcomes. Pediatr Surg Int 2008;24:167-73.

8. Lunzer H, Menardi G, Brezinka C. Long-term follow-up of children with prenatally diagnosed omphalocele and gastroschisis. J Matern Fetal Med 2001;10:385-92.

9. Saxena AK, Hülskamp G, Schleef J, Schaarchmidt K, Harms E, Wittal GH. Gastroschisis: 15 year, single-centre experience. Pediatr Surg Int 2002;18:420-24.

10. Phillips D, Raval MV, Redder C, Weiner TM. Gastroschisis, atresia, dysmotility: Surgical treatment strategies for a distinct clinical entity. J Pediatr Surg 2008;43:2208-12.

11. Fillingham A, Rankin J, Prevalence, prenatal diagnosis and survival of gastroschisis. Prenat Diagn 2008;28:1232-37.

12. David AL, Tan A, Curry J. Gastroschisis: Sonographic diagnosis, associations, management and outcome. Prenat Diagn 2008;28:633-44.

13. Castilla EE, Mastroiacovo P, Orioli IM. Gastroschisis: International epidemiology and public health perspectives. Am J Med Genet Part C Semin Med Genet 2008;148C:162-79.

14. Collins SR, Griffin MR, Arbogast PG, Walsh WF, Rush MR, et al. The rising prevalence of gastroschisis and omphalocele in Tennessee. J Pediatr Surg 2007;42:1221-24.

15. Suita S, Okamatsu T, Yamamoto T, Handa N, Nirasawa Y, et al. Changing profile of abdominal wall defects in Japan: Results of a national survey. J Pediatr Surg 2000;35:66-71.

16. Torfs CP, Velie EM, Oechsli FW, Bateson TF, Curry CJ. 1994. A population-based study of gastroschisis: Demographic, pregnancy and lifestyle risk factors. California Birth Defects Monitoring Program. Teratology 1994;50:44-53.

17. Lin S, Munsie JPW, Herdt-Losavio ML, Bell E, Druchel C, et al. The National Birth Defects Prevention Study. Maternal asthma use and the risk if gastroschisis. Am J Epidemiol 2008;168:7379.

18. Romero R, Pilu G, Jeanty P, Ghidini A, Hobbins JC, editors. Prenatal diagnosis of congenital anomalies. Connecticut: Appleton and Lange 1988;220-32.

19. Shaw A. The myth of gastroschisis. J Pediatr Surg 1975;10: 235-44.

20. deVries PA. The pathogenesis of gastroschisis and omphalocele. J Pediatr Surg 1980;15:245-51.

21. Hoyme HE, Higginbottom MC, Jones KL. The vascular pathogenesis of gastroschisis: Intrauterine interruption of the omphalomesenteric artery. J Pediatr 1981;98:228-31.
22. Hoyme HE, Jones MC, Jones KL. Gastroschisis: Abdominal wall disruption secondary to early gestational interruption of the omphalomesenteric artery. Semin Perinatol 1983;7:294-98.

23. Feldkamp ML, Carey JC, Sadler TW. Development of gastroschisis: Review of hypotheses, a novel hypothesis, and implication for research. Am Med Gent Part A 2007;143A:63952.

24. Lammer EJ, Iovanicsi DM, Tom L, Schultz K, Shaw GM. Gastroschisis: A gene-environment model involving the VEGFNOS3 pathway. Am J Med Genet Part C Semin Med Genet 2008;148C: 213-18.

25. Cedergren M, Selbing A. Detection of fetal structural abnormalities by an 11-14 weeks ultrasound dating scan in an unselected Swedish Population. Acta Obstet Gynecol Scand 2006;85:912-15.

26. Saada J, Oury JF, Vuillard E, Guibourdenche J, De Lagausie P, et al. Gastroschisis. Clin Obstet Gynecol 2005;48:964-72.

27. Salihu HM, Emusu D, Aliyu ZY, Pierre-Louis J, Druschel CM, et al. Mode of delivery and neonatal survical of infants with isolated gastroschisis. Obstet Gynecol 2004;104:678-83.

28. Puligandla PS, Janvier A, Flageole H, Bouchard S, Laberge JM. Routine vaesarean section delivery does not improve the outcome of infants with gastroschisis. J Pediatr Surg 2004;39:742-45.

29. Islam S. Clinical care outcomes in abdominal wall defects. Curr Opin Pediatr 2008;20:305-10.

30. Mahieu-Caputo D, Muller F, Jouvet P, Thalabard JC, Jouannic JM, et al. Amniotic fluid $\beta$-endorphine: A prognostic marker for gastroschisis? J Pediatr Surg 2002;37:1602-06.

31. Borgstein ES. Gastroschisis minor. J Pediatr Surg 2001;36:5155.

32. Forrester MB, Merz RD. 1999 Epidemiology of abdominal wall defects, Hawaii 1986-1997. Teratology 1999;60:117-23.

33. Houben $\mathrm{CH}$, Patel S. Gastroschisis closure: A technique for improved cosmetic repair. Pediatr Surg Int 2008;24:1057-60.

34. Kunz LH, Gilbert WM, Towner DR. Increased incidence of cardiac anomalies in pregnancies complicated by gastroschisis. Am J Obstet Gynecol 2005;193:1248-52.

35. Stoll C, Alembik Y, Dott B, Roth MP. Omphalocele and gastroschisis associated malformations Am J Genet Part A 2008;146A:1280-85.

36. Mastroiacovovo P, Lisi A, Castilla EE, Martinez-Frias ML, Bermejo E, et al. Gastroschisis and associated defects: An international study. Am J Med Genet Part A 2007;143A:66071.

37. Japaraj RP, Hockey R, Chan FY. Gastroschisis: Can prenatal sonography predict neonatal outcome? Ultrasound Obstet Gynecol 2003;21:329-33.

38. Mann S, Blinmann TA, Wilson RD. Prenatal and postnatal management of omphalocele. Prenat Diagn 2008;28:626-32.

39. Berseth CL. Disorders of the umbilical cord, abdominal wall, urachus, and omphalomesenteric duct. In: Taeusch HW, Ballard RA (Eds). The Avery's disease of the newborn (7th ed). Philadelphia: WB Saunders 1998;933-40.

40. Robinson JN, Abuhamad AZ. Abdominal wall and umbilical cord anomalies. Clin Perinatol 2000;27:947-78. 
41. Stoll C, Alembik Y, Dott B, Roth MP. Risk factors in congenital abdominal wall defects (omphalocele and gastroschisis): A study in a series of 265,858 consequtive births. Ann Genet 2001;44:20108 .

42. Mills JL, DruschelCM, Pangilinan F, Pass K, Cox C, et al. Folate-related genes and omphalocele. Am J Med Genet Part A 2005;136A: 8-11.

43. Bonilla-Musoles F, Machado LE. Gastrointestinal tract and internal abdominal wall. In: Kurjak A, Chervenak FA, Carrera JM (Eds). Atlas of fetal anomalies. Jaypee Brothers Medical Publisher 2007;174-94.

44. Gibbin C, Touch S, Broth RE, Berghella V. Abdominal wall defects and congenital heart disease. Ultrasound Obstet Gynecol 2003;21:334-37.

45. Boulton SL, Mc Kenna DS, Cly DC, Webb DC, Bantz J, et al. Cardiac axis in fetuses with abdominal wall defects. Ultrasound Obstet Gynecol 2006;28:785-88.

46. Houben CH, Farrugia MK, Drake DP. Exomphalos major suspension: A novel technique. Pediatr Surg Int 2008;24:35556.

47. Axt R, Quijano F, Boos R, Hendrick HJ, Jeberger HJ, et al. Omphalocele and gastroschisis: Prenatal diagnosis and peripartal management. A case analysis of the years 1989-1997 at the Department of Obstetrics and Gynecology, University of Homburg/Saar. Eur J Obstet gynecol Reprod Biol 1999;87:4754.

48. Vasudevan PC, Cohen MC, Whitby EH, Anumba DOC, Quarelly OWJ. The OEIS complex: Two case reports that illustrate the spectrum of abnormalities and a review of the literature. Prenat Diagn 2006;26:267-72.

49. Martinez-Frias ML, Bermejo E, Rodriguez-Pinilla E, Frias JL. Exstrophy of the cloaca and exstrophy of the bladder: Two different expression of a primary developmental field defect. Am J Med Genet 2001;99:261-69.

50. Benacerraf BR, Saltzman DH, Estroff JA, Frigoletto FD Jr. Abnormal karyotype of fetuses with omphalocele: Prediction based on omphalocele contents. Obstet Gynecol 1990;75:31731.

51. Goldstein I, Shalev E, Nisman D. The dilemma of prenatal diagnosis of bladder exstrophy: A case report and a review of the literature. Ultrasound Obstet Gynecol 2001;17:357-59.

52. Saphier JC, Gaddipati S, Applewhite LE, Berkowitz RL. Prenatal diagnosis and management of abnormalities in the urologic system. Clin Perinatol 2000;4:921-45.

53. Vogt BA, MacRae Dell K, Davis ID.The kidney and urinary tract. In: Martin RJ, Fanaroff AA, Walsh MC, (Eds). Fanaroff and Martin's Neonatal-Perinatal Medicine Diseases of the fetus and infant (8th ed). Philadelphia: Mosby Elsevier 2006;165983.

54. Wilcox DT, Chitty LS. Non-visualisation of fetal bladder: Aetiology and management. Prenat Diagn 2001;21:977-83.

55. Lee EH, Shim JY. New sonographic finding for the prenatal diagnosis of bladder exstrophy: A case report. Ultrasound Obstet Gynecol 2003;21:498-500.

56. Kavak ZN, Yitiger AB. The advantages of 3D sonography in the diagnosed and assessment of fetal abnormalities. In: Kurjak A,
Chervenak FA, Carrera JM editors. Atlas of fetal anomalies. Jaypee Brothers Medical Publisher 2007;332.

57. Gearhart JP. Bladder exstrophy: Staged reconstruction. Curr Opin Urol 1999;9:499-506.

58. Borer JG, Gargollo PC, Hendren WH, Diamond DA, Peters CA. Early outcome following complete primary repair of bladder exstrophy in the newborn. J Urol 2005;174:1674-79.

59. Gearhart JP. Complete repair of bladder exstrophy in the newborn: Complications and management. J Urol 2001;165:243133.

60. Gargollo PC, Borer JG. Contemporary outcome in bladder exstrophy. Curr Opin Urol 2007;17:272-80.

61. Hammouda HM, Kotb H. Complete primary repair of bladder exstrophy: Initial experience with 33 cases. J Urol 2004;172:144144.

62. Gobbi D, Leon FF, Tregnaghi A, Gamba PG, Midrio P. Early prenatal diagnosis of cloacal exstrophy with fetal magnetic resonance imaging. Fetal Diagn Ther 2008;24:437-39.

63. Kähler C, Humbsch K, Schneider U, Seewald HJ. A case report of body stalk anomaly complicating a twin pregnancy. Arch Gynecol Obstet 2003;268:245-47.

64. Smrcek JM, Germer U, Krokowski M, Berg C, Krapp M, et al. Prenatal ultrasound diagnosis and management of body stalk anomaly: Analysis of nine singleton and two multiple pregnancies. Ultrasoung Obstet Gynecol 2003;21:322-28.

65. Cantrell JR, Haller JA, Ravitch MM. A syndrome of congenital defects involving the abdominal wall, sternum, diaphragm, pericardium, and heart. Surg Gynecol Obstet 1958;107: 602-14.

66. Peixoto-Filho FM, Cima LC, Nakamura Pereira M. Prenatal diagnosis of pentalogy of Cantrell in the first trimester: Is 3 dimensional ultrasonography needed? J Clin Ultrasound 2008;37:112-14.

67. Chen CP. Syndromes and disorders associated with omphalocele (II): OEIS complex and pentalogy of Cantrell. Taiwan J Obstet Gynecol 2007;46:103-10.

68. Desselle D, Fellow R, Herve P, Toutain A, Lardy H, et al. Pentalogy of Cantrell: Sonographic assessment. J Clin Ultrasound 2007;35:216-20.

69. Chen CP, Shih JC, Tzen CY, Wang W. Three-dimensional ultrasound in the evaluation of complex anomalies associated with fetal ventral midline defects (Letter to the editor). Ultrasound Obstet Gynecol 2002;19:102-04.

70. Zidere V, Allam LD. Changing findings in pentalogy of Cantrell in fetal life. Ultrasound Obstet Gynecol 2008;32:835-37.

71. Källen K, Castilla EE, Robert E, Mastroiacovo P, Källen B. OEIS complex: A population study. Am J Med Genet 2000;92:62-68.

72. Keppler-Noreuil KM. OEIS complex (Omphalocele-exstrophyimperforate anus-spinal defects): A review of 14 cases. Am J Med Genet 2001;99:271-79.

73. Ben Neriah Z, Withers S, Thomas M, Toi A, Chong K, et al. OEIS complex: Prenatal ultrasound and autopsy findings. Ultrasound Obstet Gynecol 2007;29:170-77.

74. Tiblad E, Wilson RD, Carr M, Flake AW, Hedrick H, et al. OEIS sequence: A rare congenital anomaly with prenatal evaluation and postnatal outcome in six cases. Prenat Diagn 2008;28:14147. 